\title{
Rare earth element characteristics of marine carbonates from Xisha Islands, South China Sea: Implications for the effect of dolomitization on REEs
}

\author{
XIKAI WANG ${ }^{1 *}$, XIAO-Ming LiU ${ }^{1 *}$, XIAOFENG LiU ${ }^{1,2}$
}

${ }^{1}$ Department of Geological Sciences, University of North Carolina-Chapel Hill, NC 27599-3315, USA

${ }^{2}$ College of Marine Geosciences, Ocean University of China, Qingdao 266100, PR China

The differences in rare earth elements (REEs) fractionations and abundance of marine carbonates play an important role in the paleoenvironment study. However, it is argued that the primary REE characteristics preserved in dolomites could be complicated by the effect of diagenesis, especially dolomitization. Characterized as the "island of dolomites", Xisha Islands, South China Sea provide an ideal context to resolve the controversy, therefore, we analyzed the concentrations of trace elements and REEs of 24 Miocene carbonate samples (18 dolostones and 6 limestones) from the XK-1 well in Xisha Islands. The results show that PAAS-normalized REEs exhibit a uniform modern seawater-like pattern, characterized by light rare earth elements (LREEs) depletion, notable negative $\mathrm{Ce}$ and positive $\mathrm{Y}$ anomalies. The observation indicates that dolomites may preserve REE signatures of seawater, therefore dolomitization does not significantly influence REE compositions of dolomites. Furthermore, $\mathrm{Eu} / \mathrm{Eu}^{*}$ ranges from 0.80 to 1.23 with an average of 1.06 , suggesting that the influences by the post-depositional hydrothermal fluid on REEs are negligible, while the presence of terrigenous input can also be excluded by lacks of correlations between HREE/LREE values and the concentrations of $\mathrm{Al}$ and Th. However, we cannot rule out the burial diagenesis alteration since general increasing trends in $\mathrm{Y} / \mathrm{Ho}$ and HREE/LREE ratios with depth are observed. These findings suggest that dolomitization may not necessarily modify the REE patterns, and dolomites have the potential to record the primary information of past seawater when the carbonate burial history is well constrained. 